\title{
Some aspects of gas bubble disease in African catfish (Clarias gariepinus Burchell 1822)
}

J. H. Boon ${ }^{1}$, M. R. Ooms ${ }^{1}$, Th. Wensing ${ }^{2}$ and E. A. Huisman ${ }^{1}$ ( ${ }^{1}$ Department of Fish Culture and Fisheries, Agricultural University Wageningen, P.O.B. 338, Wageningen, Netherlands; 2 Clinic for Large Animal Medicin, State University, Utrecht, Netherlands)

Received 19 August 1986; accepted 14 October 1986

Abstract. The relation of gas supersaturation in the rearing water and the outbreak of gas bubble disease (G.B.D.) in African catfish was studied. Fish were susceptible to G.B.D., but seem to be less susceptible than trout and carp. Clinical characteristics are described.

Key words: gas bubble disease, supersaturation, clinical signs, African catfish.

Introduction. Gas bubble disease (G.B.D.) is caused by supersaturation of water with gas(es). This is often the result of (1) a sudden rise in watertemperature, (2) a changing pressure above the water surface, (3) an addition or surplus of gas into the water by caviation of pumps. Supersaturation of water may be followd by supersaturation of the fish blood with gas(es). Subsequent formation of air bubbles in blood culminates in obstructions and ruptures of blood vessels. The course of G.B.D. can be divided into 3 phases (Bouck, 1980): (1) fish take in gas from water until the point of equilibration; possible embolism of vessels; fish is irritated; (2) mortality caused by embolism of the ventral aorta; (3) only very resistant fish are still alive; mortality increases very slowly now caused by slowly developing secondary infections of emphysemous tissue.

Many cultured and wild fish are susceptable to G.B.D. (Bouck et al., 1976; Gray et al., 1983).

Clinical symptoms of G.B.D. are desorientation, haemorrhagics, subcutaneous emphysema and exophthalmia.

Culture of African catfish under intensive recirculation conditions is of increasing importance in the Netherlands. Since recirculation systems include higher risk for G.B.D. outbreaks, the present study is focused on the susceptibility of African catfish to G.B.D.

Material and methods. We carried out 6 one-week experiments with 50 fish each. Fish were full sibs with a weight range of $40-50 \mathrm{~g}$, and each group of 50 was kept in an aquarium seized $220 \mathrm{~cm} \times 60 \mathrm{~cm} \times 30 \mathrm{~cm}$.

Water was supplied after heating till $25^{\circ} \mathrm{C}$, by means of a hyperbaric system, which enabled application of different levels of supersaturation (S.W.). Over- and 


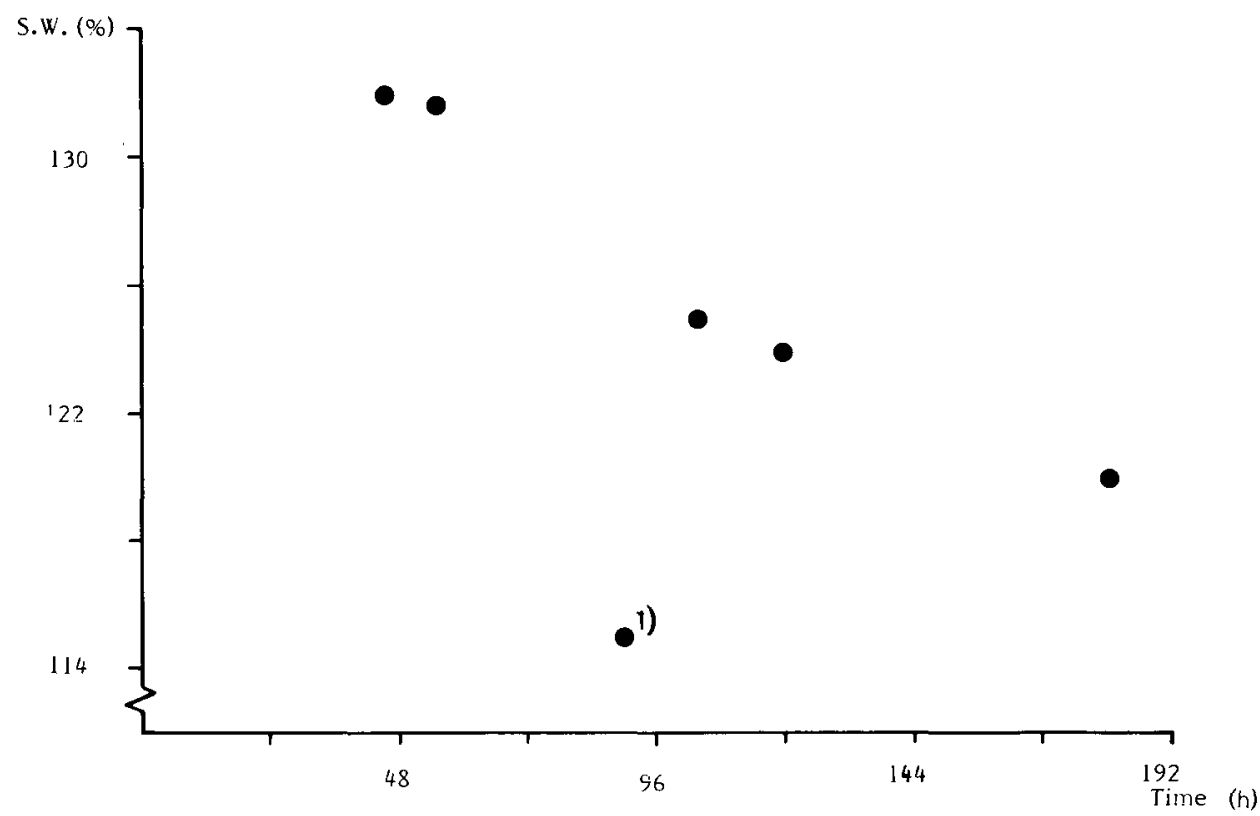

Fig. 1. Relation between LC 20 time (hours) and supersaturation of water (S.W.) 1) Value most probably influenced by fungus infection.

under-pressure (G.P.) was measured by a gasometer (Bouck, 1982). Supersaturation of water was calculated with the formula:

S.W. $=\frac{\text { B }+ \text { G.P. }-\mathrm{PH}_{2} \mathrm{O}}{\text { B }} \times 100 \%$

B

where $\quad \mathrm{B}=$ barometer pressure $(\mathrm{mm} \mathrm{Hg})$

$\mathrm{PH}_{2} \mathrm{O}=$ vapour pressure $(\mathrm{mm} \mathrm{Hg})$

During the experiments fish were not fed. Morbidity and mortality of fish were recorded. From the results of the experiments it was possible to calculate the G.B.D. mortality of fish after 96 hours of exposure (LC 96) and the time required for a G.B.D. mortality of $20 \%$ (LC 20) at a certain saturation level of gas(es) in the water.

Critical values of S.W. and overpressure were obtained by Probit analyses (Mather, 1965).

Results. Some critical values of over-pressure $(\Delta$ P), S.W. and their LC 96 are given in Table 1 . The relationship between exposure time causing $20 \%$ mortality and S.W. is given in Fig. $1(R=0.975, P<0.01)$.

Clinical symptoms found were: an apathic behaviour; an increased respiration 
Table 1. Relationship between over-pressure ( $\Delta \mathrm{P})$, supersaturation of water (S.W.) and mortality after 96 hours (LC 96 ).

\begin{tabular}{lrrr}
\hline LC 96(\%) $\rightarrow$ & 0 & 20 & 50 \\
$\Delta$ P (mm Hg) & 15 & 19 & 24 \\
S.W. $(\%)$ & 117 & 125 & 131 \\
\hline
\end{tabular}

rate; little air bubbles in the dorsal fins, mostly within $24 \mathrm{~h}$ of exposure to S.W.; air bubbles in other fins and in the subcutus combined with haemorrhagics, especially in the barbels, and exophthalmia. Obduction revealed little air bubbles in various tissues and obstruction of blood vessels by little air bubbles.

Discussion. Clarias gariepinus is susceptible to G.B.D. Symptoms found are in agreement with those found in other fish species by Clay et al. (1976). Less than a week's exposure already leads to notable mortality.

However, Clarias seems to be less susceptible to supersaturation of water than other fish. Common carp (Cyprinus carpio) and American catfish (Ictalurus melas) show higher susceptibility (Gray et al., 1983). Also trout are more susceptible to S. W. Bouck \& King (1983) found that trout needed 43 hours to reach an LC 20 at $19 \mathrm{~mm} \mathrm{Hg}$ over-pressure while in the present study Clarias needed 96 hours.

At a level below $117 \%$ supersaturation no mortality in Clarias occurred. This is a higher level than that advised by the United States Environment Protection Agency (USEPA) for shallow (110\%) water (Colt, 1984).

The difference in susceptability for G.B.D. between Clarias gariepinus and other fish species may be explained by the presence of the aborescent organs in the second and fourth branchial arches which enable 'air-breathing'.

\section{References}

Bouck, G. R., 1980. Etiology of gas bubble disease. Transactions of the American Fisheries Society 109: 703-707.

Bouck, G. R., 1982. Gasometer: an inexpensive desire for continuous monitoring of dissolved gases and supersaturation. Transactions of the American Fisheries Society 111: 505-516.

Bouck, G. R., G. A. Chapman, P. W. Schneider, Jr., \& D. G. Stevens, 1976. Observations in gas bubble disease among wild and adult Columbic river fishes. Transactions of the American Fisheries Society 105: 114-115.

Bouck, G. R. \& R. E. King, 1983. Tolerance to gas supersaturation in fresh water and sea water by steelhead trout Salmo gairdneri R. Journal of Fish Biology 23: 293-300.

Clay, A., S. Barker, R. Testaverde, R. Marcello, \& G. C. McLeod, 1976. Observations on the effects of gas embolism in captured adult Manhadenin gas bubble disease. In: D. H. Fickersen \& M. J. Schneider (Eds.), Proceedings of a workshop held at Richland, Washington, 8-9 October 1974, p. 82-84.

Colt, J. E., 1984. The computation of dissolved gas concentrations in water as function of temperature, salinity and pressure. American Fish Society, Special edition No 14.

Gray, R. H., T. L. Page, \& Suroglia, 1983. Behavioral response of carp Cyprinus carpio and black bullhead Ictalurus melas from Italy to gas supersaturated water. Environmental Biological Fisheries 8 (2) 163-167. 
Mather, K., 1965. Statistical analysis in biology. Methuen, London. $267 \mathrm{pp}$.

Stevens, E. R. \& D. J. Randell, 1967. Changes of gas concentrations in blood and water during moderate swimming activity in Rainbouw trout. Journal of Experimental Biology 46: 329-337.

This synopsis is based on a M.Sc. thesis entitled 'Gasblaasziekte bij de Afrikaanse meerval (Glarias gariepinus, Burchell 1822), door oververzadigingen van het water met gassen', Department of Fish Culture and Fisheries, Agricultural University, Wageningen, 1986, 61 pp., 15 figs., 11 tables, 75 refs. Dutch; English summary.

Available as paper copy (order R062P, $f 25$ including postage) or as microfiche (order R062M, $f 12.50$ including postage) at: NARD, clo Pudoc, P.O. Box 4, 6700 $A A$ Wageningen, Netherlands (telex 45015 blhwg). 